ably rapid. Instead of the loathing usually expressed where turpentine has been used, there was an evident desire to take this oil, and, indeed, to continue it, when the necessity for it had ceaserl.

My belief is, that almost all the essential oils would do just as much good as the turpentine, and I do not think that I shall have recourse to the turpentine again.

\section{OBSTINATE CHRONIC DISCHARGE FROM THE NOSTRIL REMOVED BY EXTRACTION OF A CARIOUS TOOTH.}

By Alered Fleischuan, Esq., M.R.C.S., L.S.A., L.M., Associate of King's College, Wrexham.

Mrss Rose S., a little girl, aged 5 years, had been troubled for about three months with a constant, though not profuse, dis charge of slightly purulent mucus from the right nostril; it appeared to be the sequel of a cold. The mucous membrane, so far as it could be examined, was healthy, and there were no indications of any morbid growth. She was ordered a strong injection of gallic acid, and took concurrently small doses of the sesquichloride of iron. The only advantage she derived was, that the discharge lost its purulent character; in amount it remained the same, though the treatment was long persevered in, and other local astringents tried. I suspected that there must be some undiscovered local irritation. Not being able, on careful examination, to find anything wrong in the nasal passages, I looked to the condition of the teeth; and, finding the right upper canine carious, removed it. The discharge was much lessened on the next day; and, in the course of a day or two, disappeared altogether.

This short account may, perchance, afford a useful hint to some one; at any rate, it is a good illustration of reflected irritation, and teaches us that oftentimes the fons et origo mali is not just where we might expect to find it.

\section{Transartions of 遍ranthes.}

\section{BIRMINGHAM AND MIDLAND COUNTIES BRANCH.}

PARAPLEGIA IN RELATION TO RENAL DISEASE.

By Willias Hinds, M.D., Birmingham.

$$
\text { [ Ticad February 10th, 1859.] }
$$

THE object of the following paper is to bring under the notice of the members of this Branch certain lesions of the nervous system in commection with some form of renal disease. I have reason to believe that these lesions, resulting in more or less paraplegia in the relation mentioned, are not so generally recognised by the profession as they deserve to be. This relation is scarcely, if at all, mentioned in some standard works on medicine; while, at the same time, there has been manifestly wanting, in many cases of paraplegia-especially, perhaps, of progressive paraplegia-a clear and sufficient pathological explanation. That this obscurity actually exists, I may refer in evillence to no less an authority than Dr. Watson, who uses the following remarkable words:- "But in very many cases we detect no alteration that seems adequate to explain the paraplegia" which "creeps on slowly and insidiously." Now, Dr. Baillie's mode of explaining some of these obscure cases of paralysis of the lower limbs, as detailed in the Medical Trans. actions-namely, by supposing serous effusion to occur in excess into the spinal canal, originating within the cranium or in the canal itself-has completely failed to stand the test of investigation.

Paraplegia then, unconnected with actual disorganisation or disease of the cord itself, being duly recognised by the experience of able and practical authorities, we are free to inquire into those other conditions of the afferent or efferent nervous agents, or those relations of the sympathetic system on which this loss of power may sometimes depend.

Amongst the most important of these lesions at present known, I believe must be ranked that relation with diseased kidney, to which I have now to direct your attention.

In the autumn of 1857 , the subject of paraplegia, in relation to disease of the urinary organs, was most ably brought before the profession in a very valuable lecture, delivered by $\mathbf{M r}$ Spencer Wells, at the Grosvenor Place School of Anatomy and Medicine. That lucid exposition I read with intense interest as probably many others did also. Several years ago, I had cases of incomplete paraplegia of the kind mentioned under treatment; but I never read these cases so satisfactorily to myself, as when I met with the facts brought forward in the lecture to which $I$ have alluded.

I propose to bring under the notice of the members two cases of this affection. One of the patients died several years ago; and I shall give the results of the post mortem examination. The other case is still living, and open to the inquiries of any gentleman who may feel disposed to investigate the case. I shall first, however, quote one or two passages from the lecture of Mr. Wells, by which we shall get a clearer insight into the nature of these cases.

Since 1845, in which year Mr. Wells's attention was firs drawn to this affection, he has had eleven cases under treat ment; and, though he does not express as much, he seems to afford ground for the presumption, that one great reason was why the attention of the physician has not been more especially called to this important affection, is the fallacy of con founding cases of disease of the mucous membrane of the bladder, resulting from actual disease or injury of the spinal marrow, with those cases in which the causation may be said to be reversed, the spinal marrow being intact, while the origin of the disease is to be looked for external to the spinal canal. Mr. Wells observes :-

"When a patient comes to you with a tottering gait, complaining of weakness in the knees, a tendency to stumble in going up and down stairs, or on any uneven ground, and a certain loss of that muscular sense which enables us to walk without watching the feet to know where to place them at every step, your first impression will be very naturally that you have to deal with a case of spinal disease. Your first impression may be correct. As you proceed with your examination of the case, you may obtain evidence of some injury to the spine; some distortion of the bones; some displacement from caries of the bodies of the vertebræ or ulceration of the intervertebral cartilages; some point at which pressure, or a sharp pass, or a hot sponge, causes pain; some history of inflammation of the cord; some indication of the pressure of a tumour, or of an aneurism on the cord; or possibly some proof that the disease is within the cranium. But you may find nothing of the kind. You have to exclude all these; and you are driven to assume a diseased condition of the lower portion of the cord, perhaps a simple atrophy, of the existence of which you have no other proof than the paraplegic symptoms I have just enumerated. Let me assure you then that you may have all these symptoms, that they may go on to complete paraplegia, and the patient may die, and that then you may find the cord perfectly healthy, so far as our examination can teach us, while the kidneys and bladder are the seat of manifest disease."

Much credit is due to Mr. Stanley, of St. Bartholomew's Hospital, who, I believe, was one of the first to bring these cases prominently before the profession. His cases were published in the Medico-Chirurgical Transactions for 1833. The following is a note of one of them.

"The first of these cases to which my attention was directed, occurred in the year 1818, in a man admitted into St. Bartholomew's Hospital on account of paraplegia, combined with re tention of urine. Both sensation and the power of motion were entirely lost in the lower limbs. On examining the spine, tenderness on pressure was discovered at the third lumbar vertebra, which, viewed in connexion with the other symptoms, was considered to indicate the existence of disease in the vertebræ; and an issue was accordingly made in this part of the spine. Considerable amendment of the symptoms followed Sensation and the power of motion were in a certain degree regained, and the retention became changed into incontinence of urine. Here the improvement ceased, the general health failed, and he gradually sank.

"On a careful examination of the body, no disease could be discovered in the containing or contained parts of the vertebral column; the vertebræ, fibro-cartilages, spinal cord, and nerves, were all perfectly sound, as were also the brain and its membranes. In one kidney were numerous small abscesses dispersed through its substance. The other kidney was gorged with blood, and its substance was much softer than natural. The mucous lining of the ureters and of the bladder was very muscular, and the muscular coat of the bladder was thickened. 